\title{
Secure Intranet Voting System for Students' Union Elections in Nigerian Tertiary Institutions
}

\author{
Bonaventure C. Molokwu' ${ }^{1}$, Monica N. Agu ${ }^{2}$ \\ ${ }^{1}$ (Department of Computer Science, University of Nigeria, Nigeria) \\ ${ }^{2}$ (Department of Computer Science, University of Nigeria, Nigeria)
}

\begin{abstract}
In virtually all tertiary institutions of Nigeria, electronic voting technologies for the conduct of students' union elections are yet to be implemented as a replacement for the existent manual voting technologies. Manual voting systems are primarily characterized by high incidences of electoral malpractices and irregularities. In this era of rapid globalization, the impact of information and communications technology (ICT) advancement in Nigeria is having numerous positive implications on students and their communities. In that regard, we sampled the opinions of users of the latter technologies, as this is crucial for the structuring and acceptance of our proposed system: Secure Intranet Voting System (SIVS). Thus questionnaires were distributed amongst randomly-selected potential voters; interviews were conducted with a subset of students' electoral commissioners and electorates at some Nigerian tertiary institutions. From our findings, we reached a consensus that the proposed system will aid in improving all electoral activities within Nigerian student communities. This paper proposes the design, development and implementation of a Secure Intranet Voting System (SIVS). The proposed system (SIVS) harnesses and utilizes the immense power of ICT techniques to create a striking impact in the way electoral activities are been conducted in Nigerian institutions. The goal of the system is tailored at establishing an efficient and effective electronic voting system aimed at improving students' democracy, and reducing electoral irregularities and malpractices in students' union elections, via a combination of robust voting technologies.
\end{abstract}

Keywords: Electronic Ballot, Electronic Voting, Intranet, SIVS, Students

\section{Introduction}

Basically, creating awareness and gathering students to participate in students' union elections has been a continual challenge for students' union governments in Nigerian tertiary institutions. In fact, voting ratios of about 30 percent are considered impressive. This students' unconcern with respect to their union elections poses great worry to the students' union electoral commission and the students' union government at large.

In an attempt to combat this apathy and increase voter participation, student governments are beginning to turn to technology for answers. Information technology staffs are getting requests to put student elections on the Web [1]. At present, students' union elections in most Nigerian tertiary institutions involve paper ballots (Manual Secret-Ballot Voting System) at a single voting location where there is control over who should vote. This voting system is both inconvenient and susceptible to error. In this era of rapid globalization, the impact of information and communications technology (ICT) advancement is becoming more prominent in Nigerian institutions [2]; and students' union electoral bodies are beginning to find ways to automate the election and electioneering processes [3]. The tremendous growth of the World Wide Web in recent years has made electronic voting the latest technology to be count on.

A voting system primarily consists of a set of methods and rules for counting votes or ballots in a bid to determine the outcome of elections. Winners may be determined by a plurality, a majority (more than $50 \%$ of the vote), an extraordinary majority (a percentage of the vote much greater than 50\%), or unanimity. Additionally, electronic voting (also known as e-voting) is a method of conducting elections in which votes or ballots are cast or collected electronically. Electronic voting is a term encompassing several types of voting, embracing both electronic means of casting a vote (or ballot) and electronic means of counting votes (or ballots). Thus the term "Intranet Voting" can be used to describe a voting or electoral process that would enable voters to cast a secure and secret ballot over a computer network within an organization (intranet) [4].

Furthermore, there are essentially two different forms of voting; they are namely:

- $\quad$ Distance voting;

- $\quad$ Presence voting.

In distance voting, the voter or electorate acts without the physical supervision of electoral commission personnel; and casts his or her vote from a place other than a polling booth, such as casting absentee ballots via mail, internet voting, or intranet voting. 
In Presence Voting, a voter or an electorate can cast his or her vote in a polling station under the physical supervision of the electoral administrators (or electoral commission personnel). Examples of presence voting are the conventional elections in polling stations or voting with e-voting machines.

\section{Problem Statement And Objectives}

An eclectic observation and study of the Manual Secret-Ballot Voting System, currently in use by the Students' Union Electoral Commission (SUEC) in University of Benin and University of Nigeria, reveals the following weaknesses or drawbacks associated with the system. They are namely:

(i) It is time-consuming.

(ii) Election results can easily be manipulated or altered via this system.

(iii) Electorates and electoral officials can easily be induced to act against their will.

(iv) This system does not ensure proper security of votes or ballots; hence cases of missing ballot boxes and votes may arise.

(v) The system is not friendly to physically-challenged electorates or voters; hence disenfranchising them from voting.

(vi) This system is very much error-prone since votes collation, votes counting and results compilation are done manually by humans.

(vii) This system encourages multiple voting.

Thus the objectives of the Secure Intranet Voting System (SIVS), in accordance with Cranor and Cytron [5] standard, are as stated below:

(i) Accuracy.

(ii) Verifiability.

(iii) Democracy.

(iv) Privacy.

(v) Convenience.

(vi) Mobility.

(vii) Reliability.

(viii) Consistency.

(ix) Social Acceptance.

(x) Effectiveness.

(xi) Efficiency.

\section{Research And Methodology}

V. Kalaichelvi and R.M. Chandrasekaran [6] assert that the implementation of electronic voting protocol for all electoral activities will aid in reducing the menace of electoral malpractices and irregularities. Also, they advocate that electronic voting shall provide a high degree of freedom, security, safety, confidence, as well as establish the essential requirements of an electronic voting system that will address crucial issues such as privacy, authentication, anonymity, duress, etc.

Also, D. Chaum [7] recommends that electronic voting, fortified with cryptographic algorithms and security techniques, is best suitable for the conduct of electoral activities globally.

Additionally, P. Norris [8] states that if citizens will not come to the polls, then newer technologies should be devised and employed that will bring the polls closer to the citizens. He also added that these newer technologies will allow users and citizens to be far more knowledgeable about public political issues, be well articulated in expressing their own opinions, and active in casting their votes.

In this regard, a general-interview-guide approach was used to extract firsthand information, via short interviews conducted with some groups of student and students' electoral commissioners from four (4) tertiary institutions in Nigeria. These institutions are as stated below:

(i) University of Benin

(ii) University of Lagos

(iii) Lagos State University

(iv) University of Nigeria

Also, in a bid to get the views and opinions of potential voters with respect to the existent voting system adopted by the Students' Union Electoral Commission (SUEC); a total of 120 questionnaires were printed for this fact-finding process. 100 questionnaires were received, as duly completed by the students, at the conclusion of the survey. The questionnaires were designed using a 3-scale response pattern comprising:

- YES;

- I DO NOT KNOW; and

- NO. 
The survey was carried out at the main campus of University of Benin, Ugbowo - Benin City, Edo State, Nigeria. Thus stated below is a summary of the survey and analysis:

Table 1: Questionnaire on the Effectiveness and Possible Improvement of Students' Electoral Activities

\begin{tabular}{|c|c|c|c|c|}
\hline $\mathbf{S} / \mathbf{N}$ & QUESTION & YES & I Do Not Know & NO \\
\hline 1. & Did you participate in the just concluded Students' Union Government (SUG) election? & 52 & 05 & 43 \\
\hline 2. & Is the current Voting System time consuming? & 67 & 20 & 13 \\
\hline 3. & Does the current Voting System encourage the participation of physically-challenged students? & 22 & 34 & 44 \\
\hline 4. & With the current Voting System, do you think election results can easily be manipulated? & 65 & 21 & 14 \\
\hline 5. & Are you satisfied with the current Manual Secret-Ballot Voting System? & 25 & 13 & 62 \\
\hline 6. & Would you like to have the current Voting System automated? & 73 & 17 & 08 \\
\hline 7. & Are you a computer literate? & 83 & 07 & 10 \\
\hline 8. & Do you have access to the Internet? & 67 & 09 & 24 \\
\hline 9. & $\begin{array}{l}\text { Do you think a migration from the Manual Secret-Ballot Voting System to an automated Voting } \\
\text { System will increase voters (students) participation in the electoral process? }\end{array}$ & 65 & 24 & 11 \\
\hline 10. & $\begin{array}{l}\text { Do you think the proposed automated Voting System will go a long way in tackling the } \\
\text { limitations of the Manual Secret-Ballot Voting System? }\end{array}$ & 72 & 16 & 12 \\
\hline
\end{tabular}

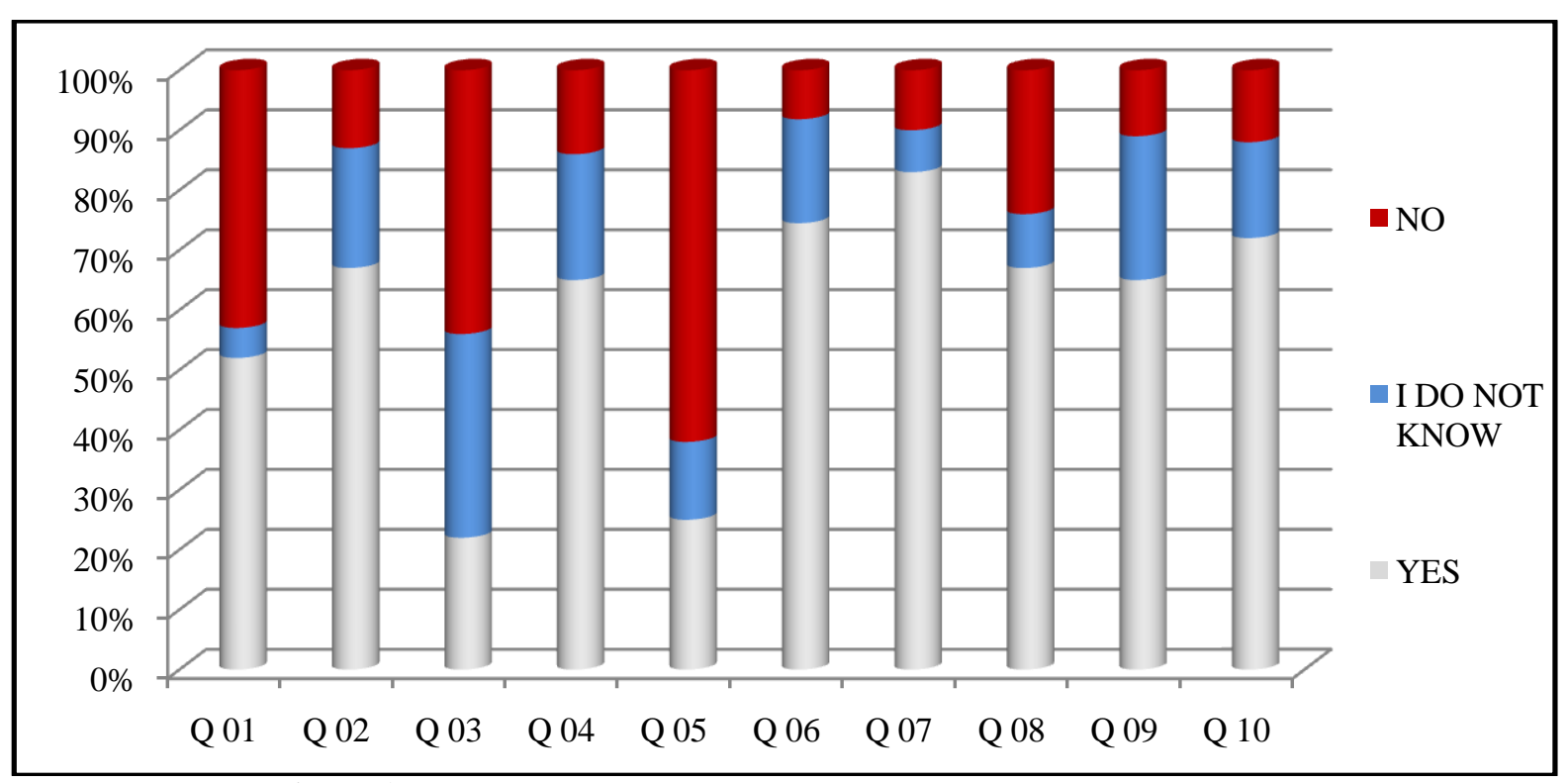

Figure 1: Cumulative and Statistical Column Chart of Questionnaire Data

Thus from our collated data and findings; it is obvious that the student communities appreciate the numerous benefits of information and communications technology (ICT) advancement. In that regard, it is expected that the implementation of the Secure Intranet Voting System (SIVS) in Nigerian tertiary institution will be very beneficial to the student communities in guaranteeing free and fair students' elections. 
IV. Design And Framework

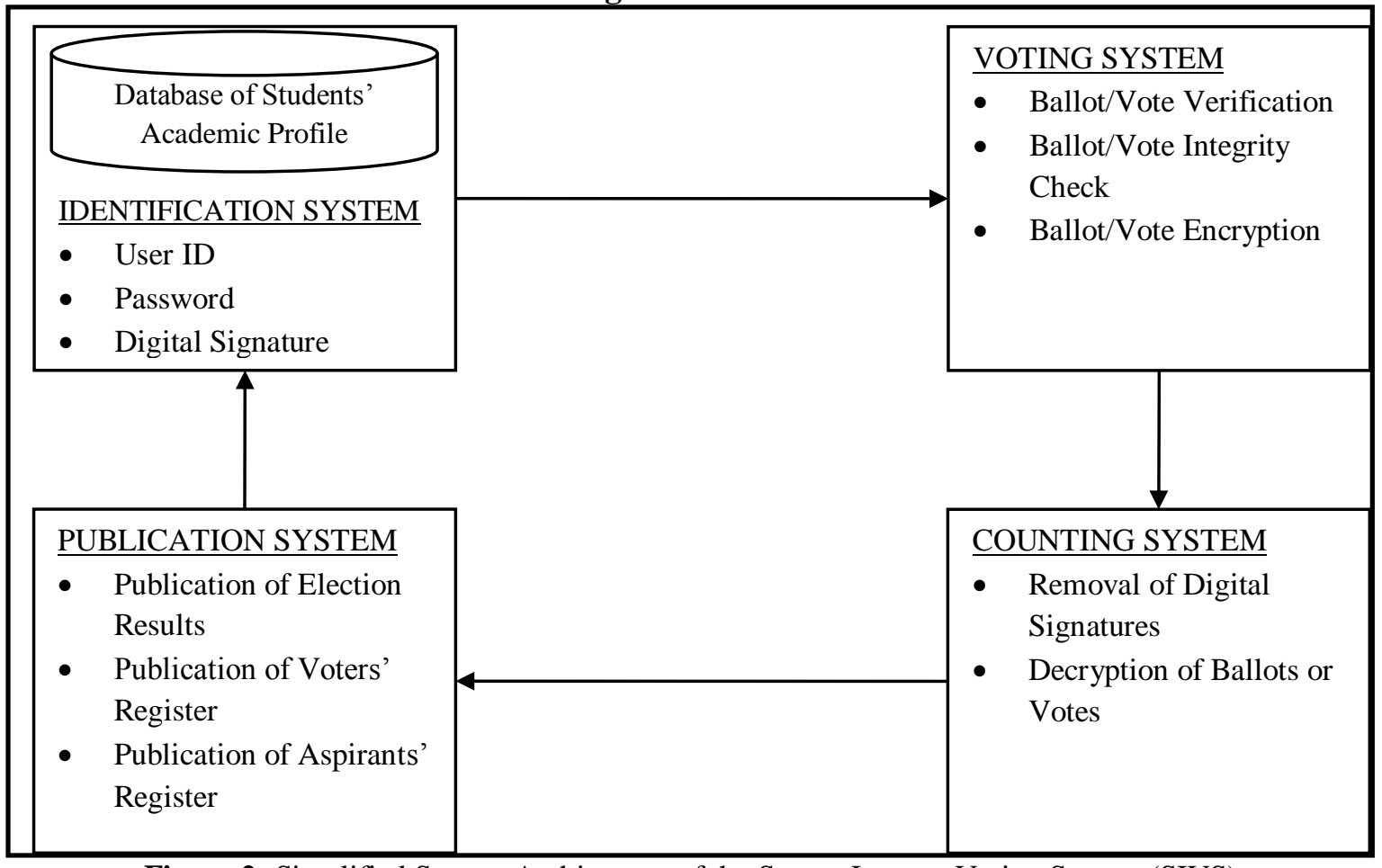

Figure 2: Simplified System Architecture of the Secure Intranet Voting System (SIVS)

With reference to the system architecture, the first phase is the Identification System. The Identification System aids in uniquely identifying each student or user of the voting system. Thus the system depends on the database of students' academic profile for user identification. During the identification process, an eligibility check based on the students' database profile is performed.

Secondly, the ballot or vote is transmitted to the Voting System; which executes an integrity check on the ballot or vote which includes some verification mechanisms. Afterwards, through a homomorphic encryption mechanism, voter anonymization is made possible.

Thirdly, the cast ballot or vote is transmitted to the Counting System. There are two established methods that can either be used to accomplish this transfer, they are namely:

(i) with a physical medium through an air-gap; or

(ii) by internal network connection.

In general, the Counting System mixes the ballots or votes before encrypting and counting in order to guarantee a high level of anonymization and security.

Finally, the fourth step is the Publication System. The results are published, for example, via the Intranet or within a Local Area Network. It is possible to publish the cast ballots or provide verification codes to enable end-to-end verification. 


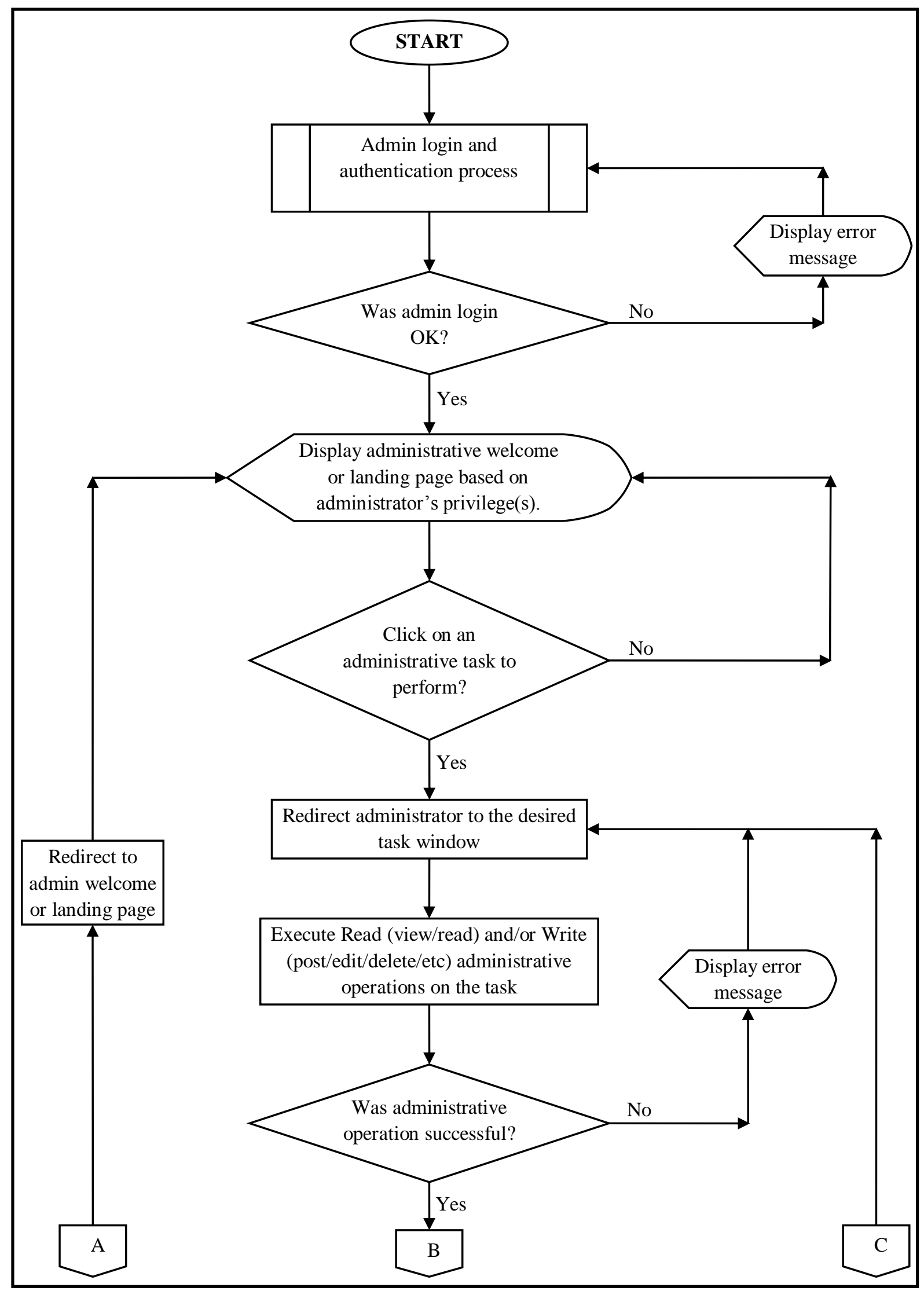




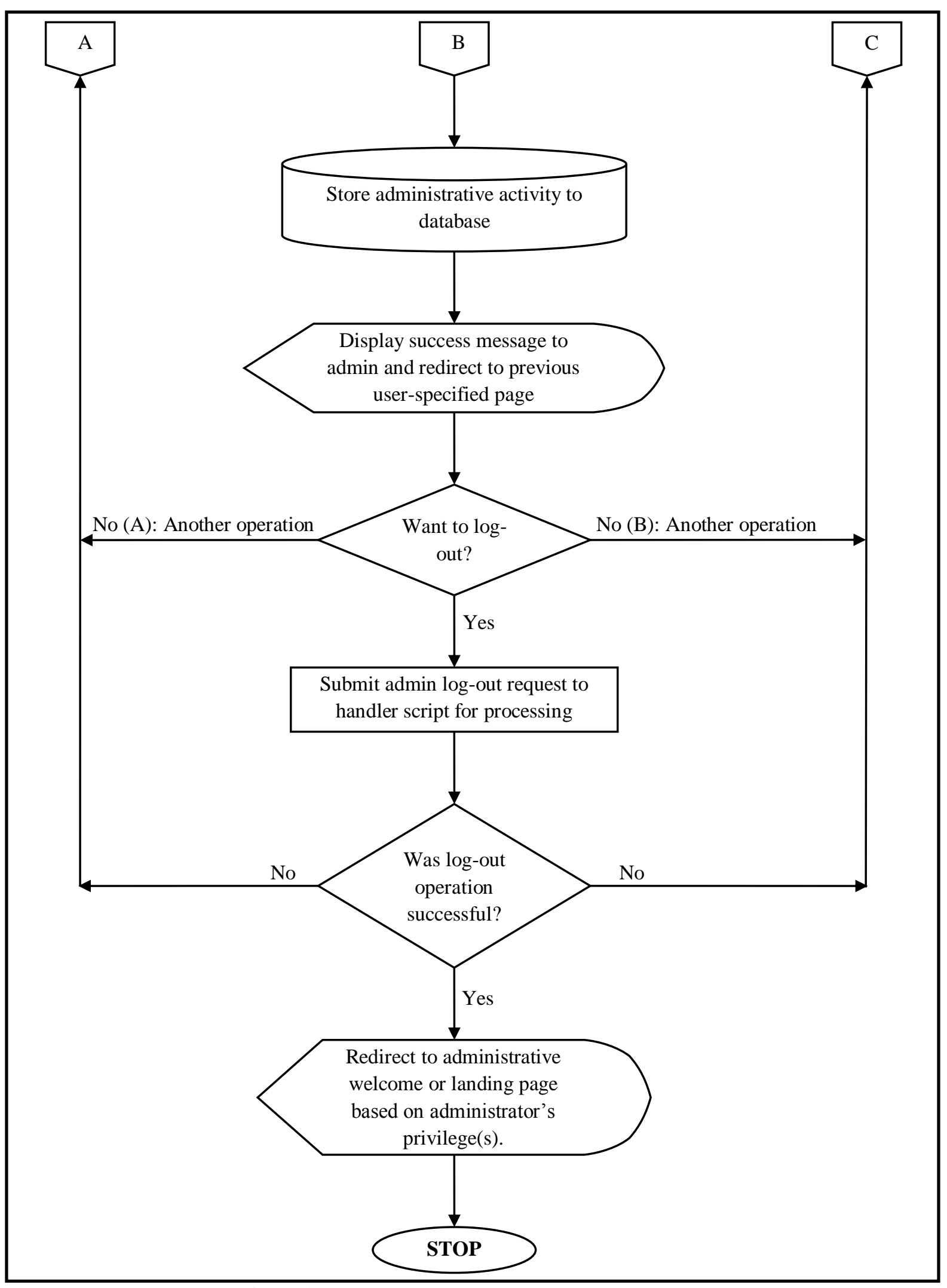

Figure 3: Generic Flowchart for Administrative Process 


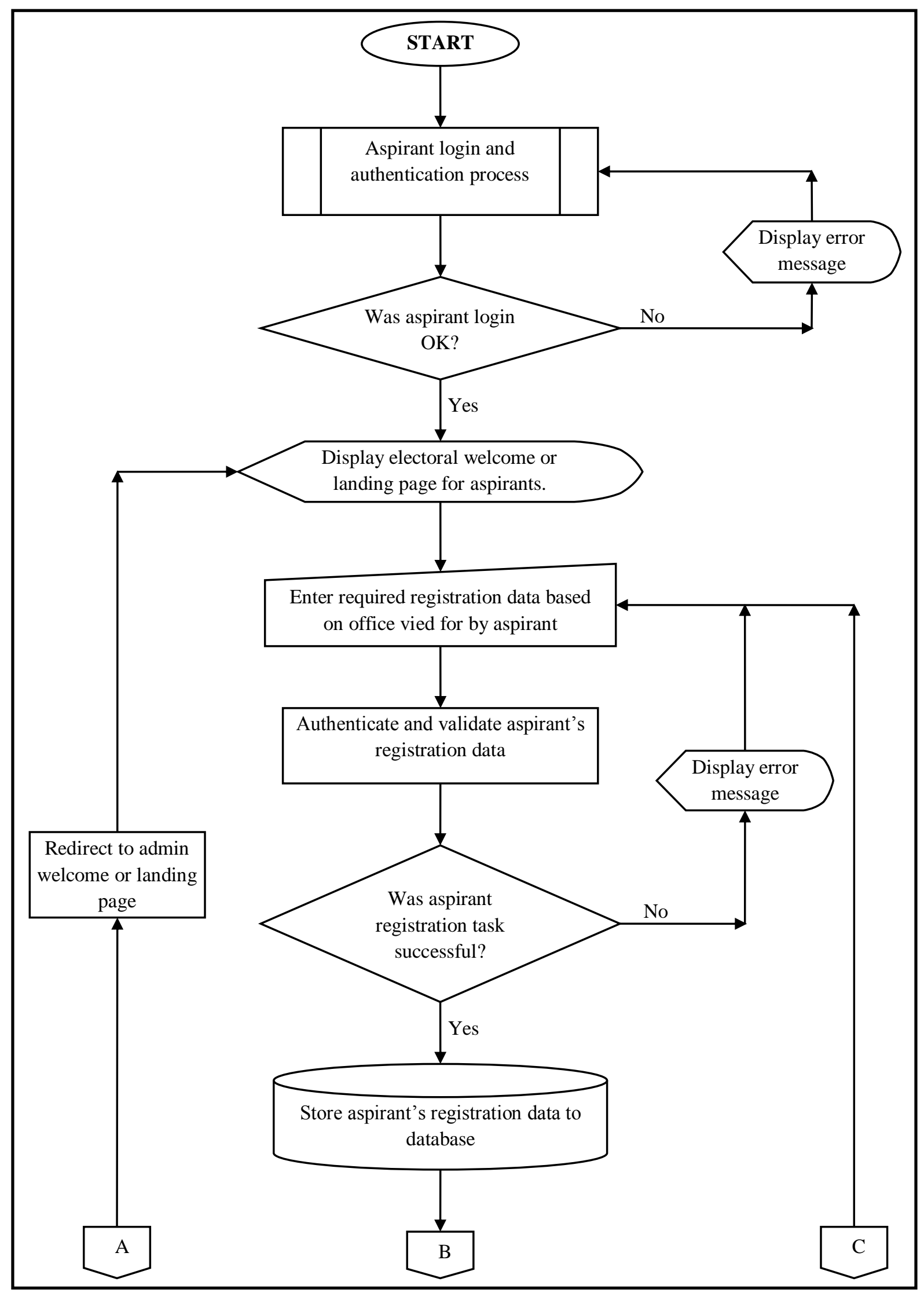




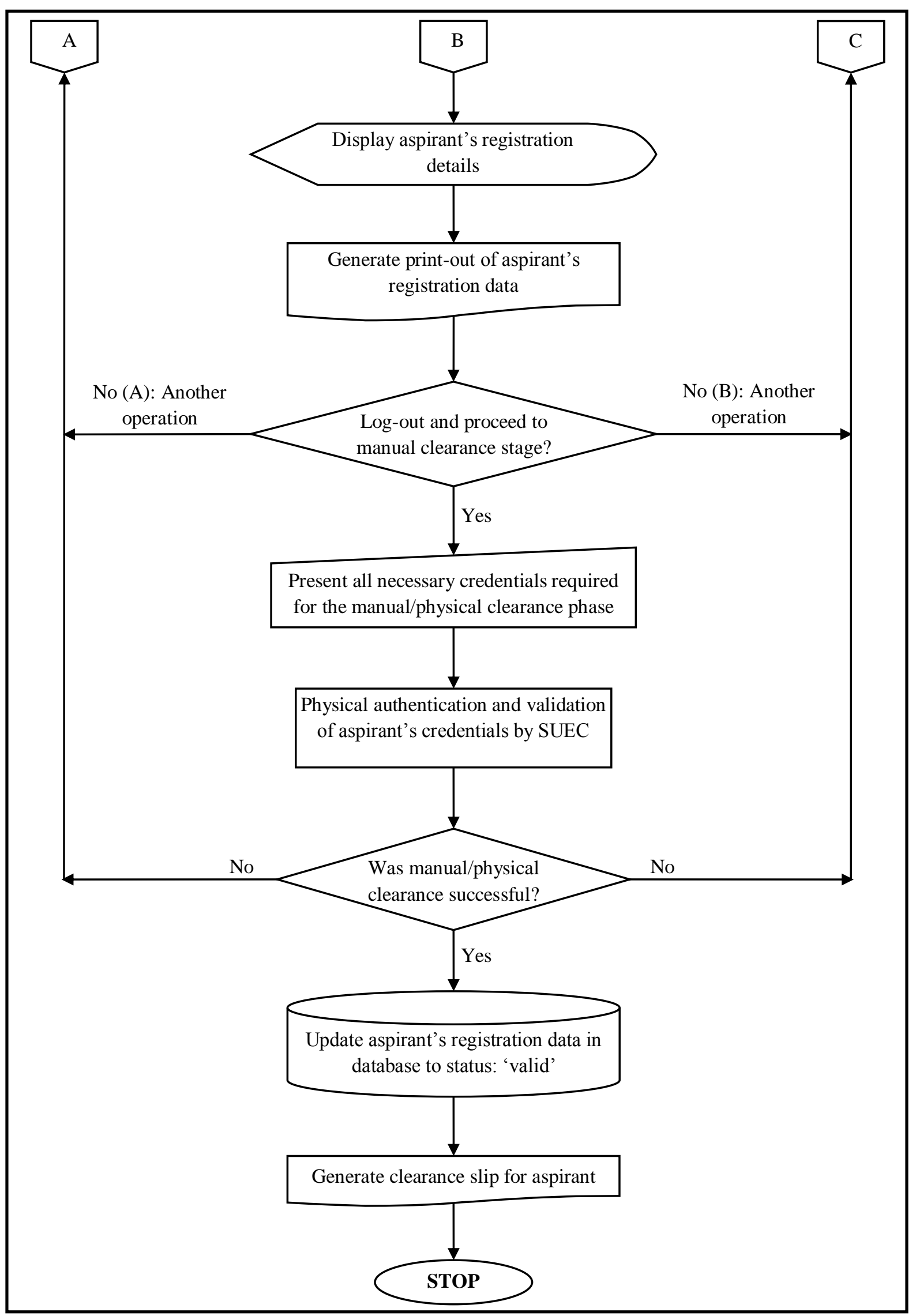

Figure 4: Generic Flowchart for Aspirant/Candidate Registration 


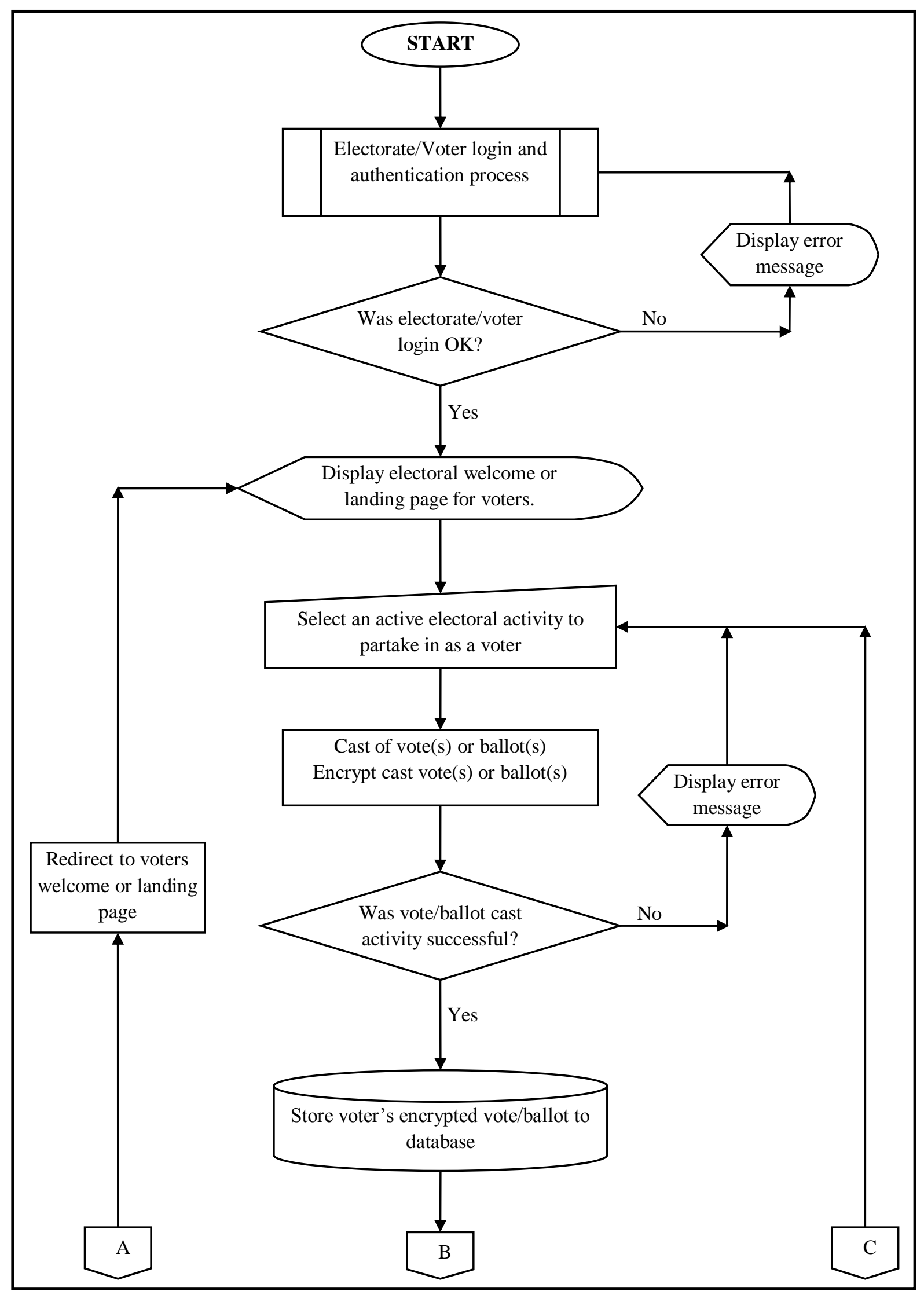




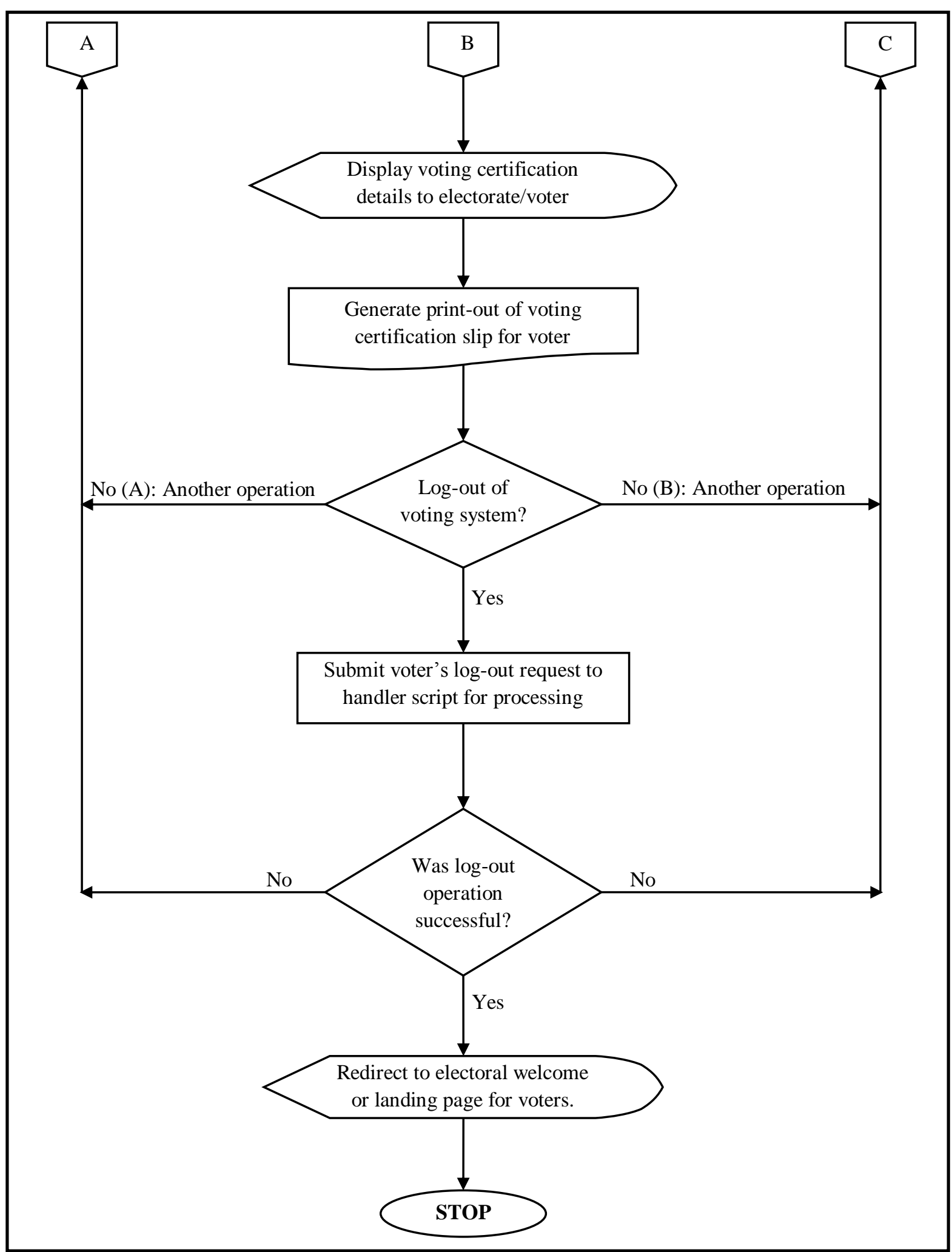

Figure 5: Generic Flowchart for Ballot/Vote Casting (Voting Process)

\section{Development And Implementation}

This phase of the system application development takes into consideration the following steps stated below: 


\subsection{Hardware and Software Interfaces}

Table 2: Hardware/Software Interfaces

\begin{tabular}{|c|c|c|}
\hline \multicolumn{3}{|c|}{ Minimum Hardware Requirements } \\
\hline $\mathbf{S} / \mathbf{N}$ & Server-Side Specification & \begin{tabular}{|r|} 
Client-Side Specification \\
\end{tabular} \\
\hline 1. & $2 \mathrm{GHz}+\mathrm{CPU}$ speed & $1 \mathrm{GHz}+\mathrm{CPU}$ speed \\
\hline 2. & $2 \mathrm{~GB}+$ of RAM & $512 \mathrm{MB}+$ of RAM \\
\hline 3. & 10GB+ database space & $512 \mathrm{MB}+$ hard-drive space \\
\hline 4. & 20GB+ hard-drive space & Internet connectivity (400kbps+ bandwidth) \\
\hline 5. & Web server (HTTP/FTP) & Personal Computer (PC) \\
\hline 6. & Database server (SQL) & \\
\hline 7. & Webmail server (SMTP) & \\
\hline \multicolumn{3}{|c|}{ Minimum Software Requirements } \\
\hline $\mathrm{S} / \mathbf{N}$ & \begin{tabular}{|r} 
Server-Side Specification \\
\end{tabular} & \begin{tabular}{|c|c|c|} 
Client-Side Specification \\
\end{tabular} \\
\hline 1. & Linux ${ }^{\circledR}$ or Windows ${ }^{\circledR}$ OS & Linux $^{\circledR}$ or Windows ${ }^{\circledR}$ OS \\
\hline 2. & Apache $^{\mathrm{TM}} 2.0+$ server (PHP 5.0+) & JavaScript-enabled web browser \\
\hline 3. & MySQL ${ }^{\mathrm{IM}} 5.0+$ server & \\
\hline 4. & Mercury $^{\mathrm{IM}} 4.0+$ server & \\
\hline
\end{tabular}

\subsection{Communication Interfaces}

(i) TCP/IP (Transmission Control Protocol/Internet Protocol);

(ii) HTTP (HyperText Transfer Protocol);

(iii) HTTPS (Secured HyperText Transfer Protocol);

(iv) FTP (File Transfer Protocol);

(v) SMTP (Small Mail Transfer Protocol); etc.

\subsection{Software Development Models}

(i) Waterfall model; and/or

(ii) Rapid Application Development (RAD) model.

\subsection{Software Development and Implementation}

Table 3: Software Development/Implementation

\begin{tabular}{|c|l|l|}
\hline S/N & Front-end Specification & \multicolumn{1}{|c|}{ Back-end Specification } \\
\hline 1. & HTML $4.0+$ & MySQL 5.0+ \\
\hline 2. & CSS $2.0+$ & PHP 5.0+ \\
\hline 3. & JQuery 1.8+ & JQuery 1.8+ \\
\hline 4. & JavaScript $1.5+$ & JavaScript $1.5+$ \\
\hline 5. & Adobe Photoshop 7.0+ & RSS $2.0+$ \\
\hline
\end{tabular}

\subsection{System Maintenance}

Routine maintenance checks and application upgrade shall be the full responsibility of the web administrator. The database administrator shall be responsible for performing routine database backup/recovery and optimization operations on the database server to boost its effectiveness and efficiency.

\subsection{User Characteristics}

(i) Technical Expertise: Users ought to be computer literates and be able to use web application.

(ii) Educational Level: Users must, at least, be an undergraduate student; a basic understanding of English Language is very necessary.

(iii) Experience: Users must be conversant with his/her institution's rules and code of conduct.

\subsection{Constraints}

(i) Additional network-security strategies or policies have to be imposed on the system application when it is deployed to a live/production server. This will protect vital data and information from unauthorized application/network access (data theft).

(ii) To improve application security, it may be helpful to deploy the system application on an intranet or extranet. However, the application can also be deployed on the Internet.

\subsection{Assumptions and Dependencies}

(i) The system application is intended for students' union electoral activities.

(ii) Users of the system are bona fide students of the institutions which operate on the application.

(iii) All users are computer literates. 


\section{Findings And Discussion}

Thus some of the goals and expected outcomes of the system application with respect to students' communities in Nigerian tertiary institutions are outlined below:

(i) Increasing the participation of students or voters in the light of falling electorate/voter participation.

(ii) Providing access to home-bound and disabled students (eligible voters); thus granting them easier access to the voting activity or process.

(iii) Electronic voting would cost less, mainly through the elimination of personnel required at polling places and all the printed materials required for the electoral activity.

(iv) Speedy and prompt implementation of the entire electoral activities.

\section{Conclusion And Future Works}

As a result of technological advancement, we are beginning to appreciate how technology may support students' (electorates') democracy. In that regard, for us to really understand the subtle effects of information and communication technology (ICT)-based tools on the students' (electorates') democratic process; we need a better knowledge of the micro-dynamics of political participation and communication, and how information and communication technology (ICT) intervenes in these processes.

Analytically, this paper has ascertained that information and communications technology (ICT) has the potential to make the act of voting more convenient. This paper has been able to present the design, development and implementation of a Secure Intranet Voting System (SIVS) for adoption in Nigerian tertiary institutions. In this regard, the system is aimed at promoting and increasing voter (student) participation rates during Students' Union elections which have been slumping in recent times. Also, the full adoption of the proposed system will result in higher efficiencies and increased accuracy during votes (ballots) counting.

Furthermore, in a bid to greatly improve the application security, it will be erudite to deploy the system application on an Intranet or Ethernet; however the system can also be deployed on the Internet.

\section{References}

[1]. P. Dempsey, Student Elections Online (Carlisle, England: Dickinson College, 2000).

[2]. B. C. Molokwu and M. N. Agu, Students' Information-exchange and Repository System for Nigerian Tertiary Institutions, African Journal of Computing \& ICT, 7(3), 2014, 53-60.

[3]. B. Oxendine, Electronic Elections (www.studentleader.com/sl_10ee.htm: Student Leader, 1999).

[4]. B. Jones, A Report on the Feasibility of Internet Voting, California Secretary of State, Sacramento, California, USA, 2000.

[5]. L. F. Cranor and R. K. Cytron, Design and Implementation of a Practical Security - Conscious Electronic Polling System, Department of Computer Science, University St. Louis, Washington, USA, 1996.

[6]. V. Kalaichelvi and R.M. Chandrasekaran, Design and Analysis of Secured Electronic Voting Protocol, Asian Journal of Information Technology, 11(2), 2012, 50-55.

[7]. D. Chaum, Advances in Cryptology: Proceedings of Crypto 83 (New York, USA: Springer, 2012).

[8]. P. Norris, Digital Divide (New York, USA: Cambridge University Press, 2001).

[9]. D. Jefferson, A. D. Rubin, B. Simons, and D. Wagner, A security analysis of the secure electronic registration and voting experiment (SERVE), http://servesecurityreport.org/paper.pdf, 2004.

[10]. B. Harris, Black Box Voting (Renton, Washington, USA: Talion Publishers, 2004).

[11]. D. Gritzalis, Secure Electronic Voting (USA: Kluwer Academic Publishers, 2002).

[12]. K. Hacker and J. V. Dijk, Digital Democracy, Issues of Theory and Practice (USA: SAGE Publications, 2000).

[13]. P. Van Den Besselaar, A. M. Oostveen, F. De Cindio, and D. Ferrazzi, Equipments with E-voting Technology: Experiences and Lessons (Amsterdam, Netherlands: IOS Press, 2003).

[14]. H. Deitel, P. Deitel, and T. Nieto, Internet \& World Wide Web: How to Program (USA: Deitel \& Associates Incorporated, 2001).

[15]. J. Greenspan, B. Bulger, MySQL/PHP Database Applications (California, USA: IDG Books Worldwide Incorporated, 2001).

[16]. L. Welling, L. Thomson, PHP and MySQL Web Development (Indianaplolis, Indiana, USA: Sams Publishing, 2001).

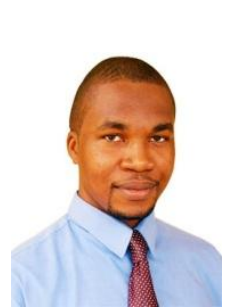

\section{AUTHORS BIOGRAPHY}

Bonaventure C. Molokwu is a certified programmer and web-application developer as well as a member of a couple of international Information and Communications Technology societies. He has over six years of experience in software-application development and programming: ranging from small-scale to enterprise applications. At the moment, he is a postgraduate of Computer Science at University of Nigeria, Nsukka. He holds a Bachelor of Science degree in Computer Science from University of Benin, Benin City, Nigeria. His areas of research include: Software Engineering and Security, Intelligent Systems and Networking. He can be reached via phone on +2348068975051 and through Email bcmolokwu@gmail.com

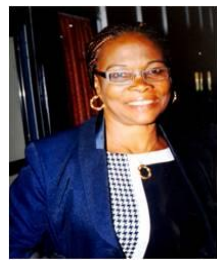

Dr (Mrs) Monica N. Agu is a Senior Lecturer at the Department of Computer Science, University of Nigeria, Nsukka. She obtained a BSC Computer Science at the University of Ibadan in 1978, Master of Science Degree in Computer Science at the University of Nigeria, Nsukka in 1995 and PhD Degree in Computer Science from Ebonyi State University, Abakaliki in 2009. Her research has focused on using Information and Communication Technology to improve the lives of people and Modelling performance of Computer Systems. She can be reached by phone on +2348039329480 and through E-mail monica.agu@unn.edu.ng 